\title{
The Vapor Pressure of Palladium
}

\author{
R. F. Hampson and R. F. Walker
}

(December 6, 1961)

\begin{abstract}
The vapor pressure and heat of sublimation of palladium were measured using a vacuum microbalance technique. The mean heat of sublimation obtained was $89.2 \pm 0.8 \mathrm{kcal} / \mathrm{mole}$. Over the temperature range of 1,294 to $1,488^{\circ} \mathrm{K}$ the measured vapor pressures may be represented by: $\log P_{\mathrm{mm}}=8.749-18655 / T$. The normal boiling point is estimated to be $3,200^{\circ} \mathrm{K}$.
\end{abstract}

The vapor pressure of palladium was measured by Haefling and Daane [1], ${ }^{1}$ using a modified Knudsen effusion technique which incorporated a microbalance. Their data vielded a mean heat of sublimation at $298{ }^{\circ} \mathrm{K}, \Delta H_{s}^{\circ}(298)$, of $80 \mathrm{kcal} / \mathrm{mole}$. Walker, Efimenko, and Lofgren [2], used the Langmuir technique with a microbalance to obtain a mean $\Delta H_{s}^{\circ}(298)$ of $103 \mathrm{kcal} /$ mole. The latter authors pointed out that since both sets of data yielded values of $\Delta H_{s}^{\circ}$ (298) which tended to vary with the temperatures at which the measurements were made, unresolved systematic errors were probably involved in both techniques.

More recently, Dreger and Margrave [3] measured the rate of sublimation by suspending a sample from a microbalance into a graphite tube furnace. The furnace approximated blackbody conditions. The mean value of $\Delta H_{s}^{\circ}(298)$ and its average deviation were 91.0 and $\pm 0.8 \mathrm{kcal} / \mathrm{mole}$. These authors suggested that erroneous assumptions were made by Walker et al., concerning the emissivity of $\mathrm{Pd}$ and that these errors could account for the disagreement between the respective sets of data. However, further investigation in this laboratory strongly indicated that a slow change in the calibration of the microbalance was responsible for the systematic errors in the measurements of Walker et al. Subsequent improvements in the design of the apparatus eliminated this problem.

The technique, sample, and experimental procedure used for the present measurements were generally similar to those recently described [4]. Two significant changes were made to reduce the uncertainty in the temperature measurements: a small hole $0.02 \mathrm{in}$. diam $\times 0.16 \mathrm{in}$. deep was drilled into the wall of the $0.085 \mathrm{in}$. diam $\times 0.75 \mathrm{in}$. long sample rods at an angle of $75^{\circ}$ to the normal (the angle of sighting with the optical pyrometer); the $U$-shaped hooks on the sapphire-rod suspension were replaced with $V$-shaped hooks. The first change permitted observations of the temperature of the sample under approximately black body conditions to be compared with observations of the surface

1 Figures in brackets indicate the literature references at the end of this paper. brightness temperature. The second change prevented the small sight-hole twisting out of the line of sight during the course of a run. It was assumed that for a substance having a sublimation coefficient of unity the sight-hole would not contribute to the effective area of the vaporizing surface.

Measurements of the rates of sublimation were made according to the procedure described [4], and were converted to equilibrium vapor pressures using the well-known Langmuir equation. The sublimation coefficient was assumed to be unity, and palladium was assumed to vaporize solely to the monomeric gaseous species.

Spectrochemical analysis of the sample showed it to be better than 99.9 percent pure with small amounts of the following as impurities: $\mathrm{Si}, \mathrm{B}, \mathrm{Cu}$, $\mathrm{Fe}, \mathrm{Pt}$, and $\mathrm{Rh}$.

The vapor pressures calculated from the measured rates of vaporization are given in the table, together with the corresponding values of $\Delta H_{s}^{\circ}$ (298). The free energy functions of Stull and Sinke [5] were used to obtain the heats of sublimation. Only those temperatures obtained from observations down the sight-hole are reported in the table. The relative values of these temperatures and the observed surface brightness temperatures were generally consistent with normal spectral emissivities assumed in the previous work [2]. Figure 1 shows a ClausiusClapeyron plot of the data given in the table.

The mean value and standard deviation of $\Delta H_{s}^{\circ}$ (298), obtained from the data of table 1 , are 89.2 and $0.2 \mathrm{kcal} / \mathrm{mole}$ respectively. The normal boiling point is estimated to be $3,200^{\circ} \mathrm{K}$.

The least squares line through the data shown in figure 1 is represented by $\log P_{\mathrm{mm}}=8.749-18655 / T$.

If the value of the sublimation coefficient is less than unity, the equilibrium vapor pressures given in table 1 are too low, and the corresponding values of $\Delta H_{s}^{\circ}(298)$ are too high. Neglecting uncertainties in the free energy functions and assuming a sublimation coefficient of unity, the overall limits of error in the absolute value of $\Delta H_{s}^{\circ}(298)$ are estimated to be $\pm 0.8 \mathrm{kcal} / \mathrm{mole}$, which corresponds to an error of \pm 35 percent in the vapor pressures. 


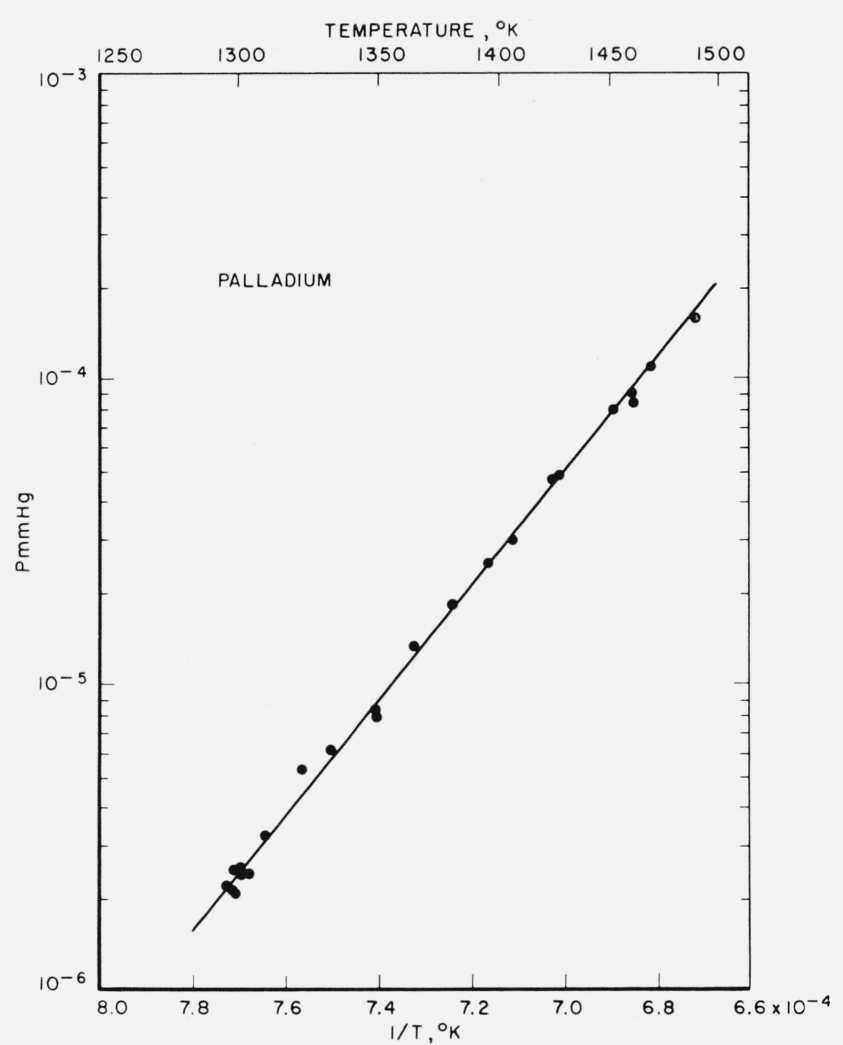

FIGURE 1. Equilibrium vapor pressure of palladium versus the reciprocal of the absolute temperature.

(Paper 66A2-149)
TABLE 1. Vapor pressures and heats of sublimation of palladium*

\begin{tabular}{|c|c|c|}
\hline Temperature & $\begin{array}{l}\text { Vapor } \\
\text { pressure }\end{array}$ & $\Delta H_{s}^{\circ}(298)$ \\
\hline $\begin{array}{l}\circ K \\
1296 \\
1294 \\
1299 \\
1302 \\
1299\end{array}$ & $\begin{array}{c}m m \mathrm{Hg} \\
2.10 \times 10^{-6} \\
2.17 \times 10^{-6} \\
2.50 \times 10^{-6} \\
2.37 \times 10^{-6} \\
\text { 2. } 40 \times 10^{-6}\end{array}$ & $\begin{array}{c}\text { kcal/mole } \\
89.3 \\
89.1 \\
89.1 \\
89.4 \\
89.2\end{array}$ \\
\hline $\begin{array}{l}1350 \\
1351 \\
1426 \\
1396 \\
1459\end{array}$ & $\begin{array}{l}\text { 8. } 22 \times 10^{-6} \\
7.69 \times 10^{-6} \\
4.78 \times 10^{-5} \\
\text { 2. } 45 \times 10^{-5} \\
\text { 8. } 21 \times 10^{-5}\end{array}$ & $\begin{array}{l}89.3 \\
89.6 \\
89.2 \\
89.3 \\
89.7\end{array}$ \\
\hline $\begin{array}{l}1488 \\
1467 \\
1450 \\
1365 \\
1297\end{array}$ & $\begin{array}{l}\text { 1. } 68 \times 10^{-4} \\
\text { 1. } 09 \times 10^{-4} \\
\text { 7. } 84 \times 10^{-5} \\
\text { 1. } 31 \times 10^{-5} \\
\text { 2. } 09 \times 10^{-6}\end{array}$ & $\begin{array}{l}89.3 \\
89.3 \\
89.3 \\
89.0 \\
89.4\end{array}$ \\
\hline $\begin{array}{l}1423 \\
1381 \\
1333 \\
1308 \\
1296\end{array}$ & $\begin{array}{l}\text { 4. } 61 \times 10^{-5} \\
\text { 1. } 80 \times 10^{-5} \\
\text { 6. } 01 \times 10^{-6} \\
\text { 3. } 19 \times 10^{-6} \\
\text { 2. } 48 \times 10^{-6}\end{array}$ & $\begin{array}{l}89.2 \\
89.2 \\
89.0 \\
89.0 \\
88.9\end{array}$ \\
\hline $\begin{array}{l}1459 \\
1406 \\
1322\end{array}$ & $\begin{array}{l}\text { 8. } 86 \times 10^{-5} \\
\text { 2. } 90 \times 10^{-5} \\
\text { 5. } 23 \times 10^{-6}\end{array}$ & $\begin{array}{l}89.5 \\
89.4 \\
88.7\end{array}$ \\
\hline
\end{tabular}

Mean $\Delta H_{s}^{\circ}(298)$ 89.2

Standard deviation

*Data are presented in experimental sequence and assume the sublimation coefficient is unity.

\section{References}

[1] J. F. Haefling and A. H. Daane, Trans. Amer. Inst. Min. (Metall.) Engrs. 212, 115 (1958).

[2] R. F. Walker, J. Efimenko, and N. F. Lofgren, Rate of vaporization of refractory substances, Physical Chemistry in Aerodynamics and Space Flight, p. 24 (Pergamon Press, 1961).

[3] L. H. Dreger and J. L. Margrave, J. Phys. Chem. 64, $1323(1960)$.

[4] R. F. Hampson and R. F. Walker, J. Research NBS. 65A (Phys. and Chem.), No. 4, 289 (1961).

[5] D. R. Stull and G. C. Sinke, Thermodynamic properties of the elements, American Chemical Society, Washington, D.C., 1956. 